\title{
The GABA Developmental Shift Is Abolished by Maternal Immune Activation Already at Birth
}

\author{
Amandine Fernandez ${ }^{1,2,3}$, Camille Dumon ${ }^{1,3}$, Damien Guimond ${ }^{1}$, \\ Roman Tyzio ${ }^{1,2,3}$, Paolo Bonifazi ${ }^{4,5}$, Natalia Lozovaya ${ }^{1}$, Nail Burnashev ${ }^{2,3}$, \\ Diana C. Ferrari ${ }^{1}$ and Yehezkel Ben-Ari ${ }^{1,2}$
}

\begin{abstract}
${ }^{1}$ Neurochlore, Ben-Ari Institute of Neuroarcheology (IBEN), Bâtiment Beret-Delaage, Parc Scientifique et Technologique de Luminy, 13288 MARSEILLE Cedex 09, France, ${ }^{2}$ Mediterranean Institute of Neurobiology (INMED), INSERM UMR1249, Marseille 13273, France, ${ }^{3}$ Aix-Marseille University UMR 1249, Marseille 13273, France, ${ }^{4}$ Biocruces Health Research Institute, Barakaldo 48903, Spain and ${ }^{5}$ IKERBASQUE: The Basque Foundation for Science, Bilbao 48013, Spain
\end{abstract}

\begin{abstract}
Address correspondence to Yehezkel Ben-Ari, Diana C. Ferrari, Neurochlore, Ben-Ari Institute of Neuroarcheology (IBEN), Bâtiment Beret-Delaage, Parc Scientifique et Technologique de Luminy, Zone Luminy Biotech Entreprises, Case 922, 163 Avenue de Luminy, 13288 Marseille Cedex 09, France. Email:
\end{abstract} ben-ari@neurochlore.fr, ferrari@neurochlore.fr

Diana C. Ferrari and Yehezkel Ben-Ari are equally contributing authors

\begin{abstract}
Epidemiological and experimental studies suggest that maternal immune activation (MIA) leads to developmental brain disorders, but whether the pathogenic mechanism impacts neurons already at birth is not known. We now report that MIA abolishes in mice the oxytocin-mediated delivery $\gamma$-aminobutyric acid (GABA) shift from depolarizing to hyperpolarizing in CA3 pyramidal neurons, and this is restored by the NKCC1 chloride importer antagonist bumetanide. Furthermore, MIA hippocampal pyramidal neurons at birth have a more exuberant apical arbor organization and increased apical dendritic length than age-matched controls. The frequency of spontaneous glutamatergic postsynaptic currents is also increased in MIA offspring, as well as the pairwise correlation of the synchronized firing of active cells in CA3. These alterations produced by MIA persist, since at P14-15 GABA action remains depolarizing, produces excitatory action, and network activity remains elevated with a higher frequency of spontaneous glutamatergic postsynaptic currents. Therefore, the pathogenic actions of MIA lead to important morphophysiological and network alterations in the hippocampus already at birth.
\end{abstract}

Key words: apical arborization, excitatory-inhibitory imbalance, hippocampal network, Poly(I:C), pyramidal neurons.

\section{Introduction}

Epidemiological studies indicate that maternal infection and inflammatory processes during pregnancy are risk factors for developmental disorders in offspring (Patterson 2002, 2009; Atladóttir et al. 2010, 2012; Brown 2012; Knuesel et al. 2014; Lyall et al. 2014; Estes and Mcallister 2016; Zerbo et al. 2015). Specifically, a bacterial infection during the second trimester of pregnancy or a viral infection in the first trimester have been correlated with the diagnosis of autism spectrum disorders (ASD) in children (Atladóttir et al. 2010). To investigate the effects of in utero exposure of the fetus to a maternal immune activation (MIA), various animal models have been designed (Dean et al. 2015; Giovanoli, Notter, et al. 2015; Solek et al. 2018; Bilbo et al. 2018). Injection in pregnant rodents of cytokines 
(Smith et al. 2007), bacterial cell wall endotoxin lipopolysaccharide (LPS) (Custódio et al. 2018; Kirsten and Bernardi 2017), or the viral mimic double-stranded RNA polyinosinic-polycytidylic acid (Poly(I:C)) generate offspring with a variety of autistic-like behavioral impairments (Smith et al. 2007; Meyer et al. 2008; Hsiao and Patterson 2011). Indeed, pregnant mice exposed to Poly(I:C) on embryonic day 12.5 (E12.5) deliver offspring that in adulthood display the 3 core symptoms of autism: reduced sociability, impaired communication skills, and stereotypic behaviors (Malkova et al. 2012). Experimental studies attempting to decipher the pathophysiological mechanisms triggered by MIA have highlighted the wide diversity of brain areas impacted by the prenatal insult, such as the neocortex (Richetto et al. 2014; Paylor et al. 2016; Kim et al. 2017; Shin Yim et al. 2017), hippocampus (Giovanoli, Weber-Stadlbauer, et al. 2016; Wolff and Bilkey 2015), and cerebellum (Shi et al. 2009), producing a variety of alterations. Particularly, Poly(I:C)induced MIA offspring was shown to exhibit pleiotropic pathophysiological disturbances. This included a loss of neuronal layer identity with somatosensory cortical disorganized patches (Kim et al. 2017; Shin Yim et al. 2017); a reduction of parvalbumin interneurons' perineural nets (Paylor et al. 2016) and an altered GABAergic ( $\gamma$-aminobutyric acid (GABA)) transcriptome (Richetto et al. 2014) leading to decreased GAD67 (glutamate decarboxylase) expression in the prefrontal cortex; and in the hippocampus, synaptic deficits (Giovanoli, Weber-Stadlbauer, et al. 2016) and alterations of place cell firing (Wolff and Bilkey 2015). However, whether MIA hinders developmental sequences of ionic currents is not known. This is important as perturbation of developmental sequences might deviate their normal course, leading to misplaced/misconnected neurons and aberrant networks, a concept known as neuroarcheology (Ben-Ari 2008). Indeed, neurons with immature features might constitute a leading pathogenic mechanism perturbing relevant brain network oscillations. In keeping with this hypothesis, Corradini and colleagues have recently shown that the developmental GABA excitatory to inhibitory shift is not present in cortical neurons of MIA offspring, leading to paradoxical excitatory actions of GABA in P20 rodents (Corradini et al. 2018). However, whether these alterations are present earlier and in particular at birth is not known.

Birth is a highly complex and stressful event with a high degree of vulnerability (Boksa et al. 2006; Chudal et al. 2014; Say et al. 2016; Brander et al. 2017; Wang et al. 2017). We reported in earlier studies that birth is associated with a neuroprotective oxytocin-mediated abrupt reduction of intracellular chloride $\left(\left[\mathrm{Cl}^{-}\right]_{\mathrm{i}}\right)$ allowing for hyperpolarizing actions of GABA (Tyzio et al. 2006). This is abolished in Fragile X (FRX) and intrauterine valproic acid (VPA) rodent models of ASD, and the effects are persistent with GABA exciting neurons also in prewean (P14-15) juvenile offspring (Tyzio et al. 2014). In addition, maternal administration of the NKCC1-specific antagonist bumetanide shortly before and during delivery restored the hyperpolarizing and inhibitory actions of GABA in prewean juvenile offspring and attenuated behavioral deleterious sequels (Eftekhari et al. 2014; Tyzio et al. 2014). These results suggest that GABA alterations already present at birth could lead to long-term consequences and that restoring the correct polarity of GABA actions might constitute an early preventive treatment.

We now report that Poly(I:C)-induced MIA alters the transient excitatory to inhibitory switch of GABA at birth due to higher $\left[\mathrm{Cl}^{-}\right]_{\mathrm{i}}$ levels as attested by measures of the $\mathrm{GABA}_{\mathrm{A}} \mathrm{R}$ driving force and its restoration by bumetanide. In addition, pyramidal neurons of the hippocampal CA3 region at birth present longer and abnormally sinuous apical tree in MIA offspring. Hippocampal network activity is also altered, with increased frequency of glutamatergic postsynaptic currents and a higher pairwise correlation of firing onset in CA3 pyramidal neurons. These effects are persistent, with excitatory GABA action at P14-15, and higher frequency of glutamatergic postsynaptic currents leading to a long-lasting inhibitory versus excitatory imbalance in MIA offspring. Altogether, our work shows that an in utero insult such as Poly(I:C)-induced MIA produces major physiological, morphological, and hippocampal network changes already at birth.

\section{Material and Methods}

\section{Animals and MIA Induction}

All animal experiments were carried out according to the guidelines set by the European Communities Council Directive (2010/63/EU). Time-pregnant female C57BL6/J mice at embryonic day 6-8 (E6-E8; Charles River Laboratories) were housed on arrival in an ABSL2 animal-housing facility with ad libitum access to food and water under a $12 \mathrm{~h} / 12 \mathrm{~h}$ light/dark cycle. Mice were left undisturbed until the day of MIA induction. Poly (I:C) $(20 \mathrm{mg} / \mathrm{kg}$, polyinosinic-polycytidylic acid potassium salt, Sigma-Aldrich) or an equivalent volume of sterile saline solution was administered to the pregnant dams at E12.5 by intraperitoneal injection as described previously (Hsiao and Patterson 2011). For the injection, Poly(I:C) was dissolved in sterile saline to a final concentration of $5 \mathrm{mg} / \mathrm{mL}$.

\section{Acute Brain Slices}

Brains from P0 and P14-15 pups were removed and immersed into ice-cold solution containing (in $\mathrm{mM}$ ): 132.5 choline chloride, $2.5 \mathrm{KCl}, 1.23 \mathrm{NaH}_{2} \mathrm{PO}_{4}, 3 \mathrm{MgCl}_{2}, 0.7 \mathrm{CaCl}_{2}, 25 \mathrm{NaHCO}_{3}, 8$ glucose. Horizontal hippocampal brain slices (300-400 $\mu \mathrm{m}$ thick) were cut on a vibratome (VT1200 Leica Microsystems). Slices were then left to recover for $1 \mathrm{~h}$ at room temperature $\left(22-25^{\circ} \mathrm{C}\right)$ in artificial cerebrospinal fluid (aCSF) containing (in $\mathrm{mM}$ ): $126 \mathrm{NaCl}, 3.5 \mathrm{KCl}$, $1.2 \mathrm{NaHPO}_{4}, 2 \mathrm{CaCl}_{2}, 1.3 \mathrm{MgCl}_{2}, 11$ glucose, $25 \mathrm{NaHCO}_{3}$ (pH 7.4). All solutions were bubbled with $95 \% \mathrm{O}_{2} / 5 \% \mathrm{CO}_{2}$.

\section{Electrophysiology}

For electrophysiological recordings of CA3 pyramidal neurons, slices were placed in a conventional fully submerged chamber superfused with aCSF at a rate of $2-3 \mathrm{~mL} / \mathrm{min}$ at room temperature.

\section{Single-channel Voltage Clamp Recordings}

The driving force of $\gamma$-aminobutyric acid type A receptor $\left(G_{A B A_{A}} R\right)$ was estimated $\left(D F_{G A B A}\right)$ by single-GABA $A_{A} R$ channel recordings in cell-attached configuration using an EPC-10 amplifier (HEKA Elektronik Dr. Schulze $\mathrm{GmbH}$ ). Patch pipette solution contained (in $\mathrm{mM}$ ): $120 \mathrm{NaCl}, 5 \mathrm{KCl}, 20 \mathrm{TEA}-\mathrm{Cl}, 54-$ aminopyridine, $0.1 \mathrm{CaCl}_{2}, 10 \mathrm{MgCl}_{2}, 10$ glucose, 10 HEPES-NaOH, pH 7.2-7.3 (with GABA at $5 \mu \mathrm{M}$ ). Abnormal NKCC1-dependent intracellular chloride accumulation was tested with acute application of the specific NKCC1 antagonist bumetanide. Briefly, $\mathrm{DF}_{\mathrm{GABA}}$ was determined on pyramidal cells before and after a $15 \mathrm{~min}$ bath application of bumetanide $(10 \mu \mathrm{M}$, SigmaAldrich). Recordings were digitized and analyzed as described previously (Khazipov et al. 1995; Tyzio 2003).

\section{Whole-cell Recordings}

Whole-cell recordings were performed with a Multiclamp 700B amplifier (Molecular Devices) and EPC-10 amplifier (HEKA 
Elektronik Dr. Schulze GmbH). Data were acquired at $10 \mathrm{kHz}$ and filtered at $2.4 \mathrm{kHz}$. Patch pipette solution contained (in $\mathrm{mM}$ ): $130 \mathrm{~K}$-gluconate, $10 \mathrm{Na}$-gluconate, $7 \mathrm{NaCl}, 4 \mathrm{Mg}$-ATP, 10 HEPES, 4 phosphocreatine, 0.3 Na-GTP, pH 7.3 with $\mathrm{KOH}$. 0.5-1\% biocytin (Sigma-Aldrich) was added to the pipette solution for post hoc morphological reconstruction at PO (see below). Pipette resistance was 6-8 M $\Omega$. At P15, spontaneous glutamatergic postsynaptic currents (sGlu PSCs) were recorded for $15 \mathrm{~min}$ at the reversal potential for GABAergic currents $-75 \pm 2 \mathrm{mV}$. Actual reversal potential for GABA currents was detected experimentally by changing the holding potential step by step (around $\mathrm{V}_{\mathrm{h}}=-75 \mathrm{mV}$ ) with increment $1 \mathrm{mV}$, and the potential at which the sGABA current (outward) was zero was taken as a holding potential for recording of sGlu PSCs. At P0, experimentally detected actual reversal potential was around $-70 \mathrm{mV}$.

Spontaneous GABAergic postsynaptic currents (sGABA PSCs) were recorded for $15 \mathrm{~min}$ at $+10 \pm 2 \mathrm{mV}$ where the glutamatergic currents are reversed or negligible. Reversal potential for GABA currents was detected experimentally by changing the holding potential step by step (around $V_{h}=+10 \mathrm{mV}$ ) with increment $1 \mathrm{mV}$, and the potential at which the sGlu currents (inward currents) was zero was taken as a holding potential for recording of sGABA PSCs.

After recording, data were filtered using a Bessel low-pass $500 \mathrm{~Hz}$ filter to reduce the root-mean-square (RMS) noise and improve the signal-to-noise ratio and analyzed using Clampfit 10.4 (Molecular Devices) and Mini Analysis 6.0 (Synaptosoft Inc). The threshold amplitude for event detection was set as $4 \mathrm{pA}$ for sGlu PSCs and $30 \mathrm{pA}$ for sGABA PSCs. Cumulative distribution was obtained using Mini Analysis 6.0 and averaging was performed in OriginPro (OriginLab).

The following experimental parameters were similar between groups: animal's age, cell depth, number of events analyzed for P14-15 sPSCs (400 events) and recording duration analyzed for P0 sPSCs (5 min).

\section{Intrinsic Properties}

The membrane capacitance $(\mathrm{Cm})$ and resting membrane potential (i.e., membrane potential at $I=0, V_{\text {rest }}$ ) were measured immediately after establishing the whole-cell configuration. Action potential firing pattern of the cell was recorded at least $5 \mathrm{~min}$ after the start of the dialysis to allow intracellular medium diffusion into the cell. The holding current $\left(\mathrm{I}_{\mathrm{h}}\right)$ and the series resistance $\left(R_{s}\right)$ in response to a $5 \mathrm{mV}$ pulse were monitored throughout the recording. Criteria for data inclusion for analysis were leakage current $<-50 \mathrm{pA}$ at $\mathrm{V}_{\text {hold }}=-70 \mathrm{mV}, R_{\mathrm{s}} \leq$ $25 \mathrm{M} \Omega$, and $R_{\mathrm{S}}$ change over recording time $\leq 20 \%$. Additionally, cells were included for analysis if their firing pattern was typical of a pyramidal cell. Post hoc biocytin revelation provided the cells' morphology and location within the hippocampal CA3 pyramidal cell layer at PO.

\section{Cell-attached Recordings}

Cell-attached recordings of action potential firing were performed with a Multiclamp 700B amplifier (Molecular Devices) on P14-15 hippocampal slices using 7-10M $\Omega$ borosilicate glass pipettes filled with aCSF. After a baseline period of at least $10 \mathrm{~min}$, isoguvacine (specific $\mathrm{GABA}_{\mathrm{A}} \mathrm{R}$ agonist, $10 \mu \mathrm{M}$, SigmaAldrich) was bath applied for 120-140 s and washed for $15 \mathrm{~min}$. Baseline spiking frequency was defined as $100 \%$ of spiking activity. Spiking frequency during the application of isoguvacine was calculated as a percentage of the baseline spiking frequency. Firing activities were analyzed offline with Mini
Analysis 6.0 (Synaptosoft Inc). To rule out the possibility of artifactitious spiking variations, only cells showing a maximum difference of $30 \%$ spiking from the baseline period compared with wash were included in the analysis. The threshold amplitude for detecting action potentials was set at twice the baseline noise.

\section{Calcium Imaging}

\section{Recordings}

After $1 \mathrm{~h}$ recovery, P0 slices were incubated for $25-30 \mathrm{~min}$ in a lightproof oxygenated chamber heated at $37^{\circ} \mathrm{C}$ filled with $2.5 \mathrm{~mL}$ aCSF with $25 \mu \mathrm{L}$ Fura-2AM solution containing: $50 \mu \mathrm{g}$ Fura-2AM (Molecular Probes, Life Technologies), $48 \mu \mathrm{L}$ DMSO (Sigma), $2 \mu \mathrm{L}$ pluronic acid (Life Technologies). Slices were then left to recover for $30 \mathrm{~min}$ to $1 \mathrm{~h}$ before recording under continuously superfused oxygenated aCSF $\left(\mathrm{O}_{2} / \mathrm{CO}_{2}-95 \% / 5 \% ; 3 \mathrm{~mL} / \mathrm{min}\right)$ heated at $37^{\circ} \mathrm{C}$. Slices were imaged using a multibeam 2-photon laser scanning apparatus (Trimscope-LaVision Biotec) coupled to an Olympus microscope (wide numerical aperture 20X, NA 0.95, Olympus) as described previously (Crépel et al. 2007; Dehorter 2011). Laser scanning was performed with a $475 \times$ $355 \mu \mathrm{m}$ scanfield using a CCD camera (LaVision Imager 3QE) with a $4 \times 4$ binning, time resolution of $137 \mathrm{~ms}$, and a duration of 1000 frames per recorded movie.

\section{Analysis}

Calcium imaging recordings were preprocessed using an upgraded version of the custom designed MATLAB (MathWorks) software "Hippo" previously described (Crépel et al. 2007; Bonifazi et al. 2009) to identify the cell contours, extract the average calcium signals from the detected cell areas, and mark the onsetsoffsets of the calcium events.

For each movie, active cells were defined as those exhibiting calcium events with a minimum $5 \%$ fluorescence deflection within the recording time. Calcium plateaus were defined as long-lasting events during which fluorescence deflection was sustained for at least 30 frames (Crépel et al. 2007; Ferrari et al. 2012).

To calculate the pairwise correlation between active cells, the calcium signal of each cell was converted into a binary time series preserving the temporal resolution, with the ones marking the time window between onset and offset of each calcium event. The correlation between time series was calculated according to the following equation:

$$
C_{i j}=\frac{\sum_{t=1}^{T} S_{i}(t) * S_{j}(t)}{\sqrt{N_{i} * N_{j}}}
$$

where $t$ is the frame number, $S_{i}$ and $S_{j}$ are the time series of cell $i$ and $j$, respectively, $T$ is the total number of frames, $N_{i}$ and $N_{j}$ are the total number of ones in the time series of neuron $i$ and $j$, respectively. Note that this is the equivalent of calculating the cosine between the 2 vectors representing the binary time series.

To compute the correlation between the plateau cells, similarly to what was described by Crépel et al., 2007, the binary time series of the event's onsets for the plateau cells was smoothed with a Gaussian ( $\sigma=1$ frame). The correlation was then calculated according to equation 1 and the significance of each correlation value with an accuracy of $P<0.001$ was estimated from surrogate data sets, in which the events were randomly reshuffled in time. 


\section{Biocytin-filled CA3 Pyramidal Neurons Morphological Reconstruction}

After whole-cell patch clamp recording, P0 slices were immediately immersed in Antigenfix (DiaPath) for overnight fixation. Slices were then rinsed 3 times for $10 \mathrm{~min}$ in 1X-PBS before being stored at $4^{\circ} \mathrm{C}$ in $1 \mathrm{X}$-PBS $0.01 \%$ azide until biocytin revelation. For biocytin revelation, slices were first rinsed as described above, incubated in blocking solution (1X-PBS, 0.3\% Triton, $5 \%$ Normal Goat Serum) at room temperature for $1 \mathrm{~h}$ under gentle agitation, and incubated overnight at $4^{\circ} \mathrm{C}$ in Streptavidin-Alexa 555 (1/1000, Thermo Fisher-Invitrogen) in blocking solution under gentle agitation. The following day slices were rinsed as previously, incubated for $10 \mathrm{~min}$ in $1 \mathrm{X}$-PBS with $1 / 1000$ Hoechst (Sigma-Aldrich), and rinsed before mounting (Fluoromount-GTM Slide Mounting Medium, Electron Microscopy Sciences). Neurons were stack-imaged with a Leica SP5-X confocal microscope (Leica Microsystems) at a $400 \mathrm{~Hz}$ frequency, $1024 \times 1024$ pixels wide field, Airy 1 pinhole, and $0.5 \mu \mathrm{m}$ steps. Neurons were reconstructed on image-stacks using the Fiji software (Schindelin et al. 2012) (open-source platform) semiautomated Plugin Simple Neurite Tracer (Longair et al. 2011). The evaluation of neurons' apical arbor complexity was conducted by Sholl analysis (Sholl 1953) with Fiji. This analysis quantifies the number of dendritic intersections as a function to the radial distance from the soma center. The morphological parameters analyzed comprised the ending radius, the number of nodes (Libersat and Duch 2002), and the critical radius (GoutyColomer et al. 2018). Only cells showing a single apical primary dendrite were considered for morphological analysis.

\section{Statistics}

$\mathrm{DF}_{\mathrm{GABA}}$ data at $\mathrm{P0}$ and P14-15 were analyzed by 2-tailed T-test. Statistics for sGlu and sGABA PSCs frequency and amplitude at P0 and P14-15, calcium percentage of active cells and plateau cells, morphological metrics and intrinsic pyramidal cell properties were performed by Mann-Whitney test. For cell-attached P14-15 data, paired 2-tailed T-test was conducted within groups to compare spiking frequency of the same cell before and after application of isoguvacine. Values are indicated as mean \pm S.E. M. Differences were considered significant when $P \leq 0.05$.

\section{Results}

\section{Depolarizing Action of GABA and Altered Apical Dendritic Arborization in CA3 Pyramidal Neurons at Birth After MIA}

To test the hypothesis that Poly(I:C)-induced MIA offspring present physiological alterations on the day of birth (postnatal day $0, P 0$ ), we evaluated GABAergic activity. We used noninvasive cell-attached $\mathrm{GABA}_{\mathrm{A}} \mathrm{R}$-mediated single-channel current recordings to estimate the driving force of $\mathrm{GABA}\left(\mathrm{DF}_{\mathrm{GABA}}\right)$. In CA3 pyramidal neurons from $P 0$ saline-treated animals, the $\mathrm{DF}_{\mathrm{GABA}}$ was slightly hyperpolarizing $(-1.2 \pm 1.1 \mathrm{mV}$, Fig. $1 \mathrm{~A}, \mathrm{~B})$. In contrast, the $\mathrm{DF}_{\mathrm{GABA}}$ of $\mathrm{PO}$ MIA offspring was depolarizing $(9.4 \pm 1.5 \mathrm{mV}$; 2-tailed T-test, $P<0.001$; Fig. $1 \mathrm{~A}, \mathrm{~B})$. Thus, the birth-associated transient GABA hyperpolarizing switch (Tyzio et al. 2006) is abolished in MIA offspring. Bath application of bumetanide (specific antagonist of the NKCC1 chloride importer) decreased intracellular chloride $\left(\left[\mathrm{Cl}^{-}\right]_{\mathrm{i}}\right)$ and the $\mathrm{DF}_{\mathrm{GABA}}$ in saline-treated $(-2.8 \pm 0.9 \mathrm{mV}$; 2-tailed T-test, $\mathrm{P}<$ $0.001)$ and MIA-treated $(-2.1 \pm 1.2 \mathrm{mV}$; 2-tailed T-test, $P<0.001$;
Fig. 1B) pyramidal neurons, switching in the latter the polarity of GABA from depolarizing to slightly hyperpolarizing. Wholecell voltage clamp recordings were then performed to determine intrinsic, passive and firing properties. These properties including passive membrane properties, firing and action potential properties were not different in control and MIAtreated pups (Supplementary table 1).

Biocytin-filled neurons were post hoc reconstructed for morphological analysis (Fig. $1 \mathrm{C}$ and Supplementary Fig. 1). MIA increased the total apical dendrites length $(1210 \pm 80.13 \mu \mathrm{m}$ vs. $706.7 \pm 89.56 \mu \mathrm{m}$; Mann-Whitney test, $P<0.001$; Fig. $1 D)$, and the ending radius $(136.3 \pm 6.30 \mu \mathrm{m}$ vs. $103.9 \pm 9.16 \mu \mathrm{m}$; MannWhitney test, $P<0.005$; Fig. $1 E$ ) of P0 CA3 pyramidal neurons compared with saline neurons. Furthermore, even if the number of nodes $(21.44 \pm 3.235$ vs. $25.67 \pm 2.297$; Mann-Whitney test, not significant; Fig. $1 F)$ and critical radius (58.82 \pm 8.35 vs. $74.23 \pm 5.5$; Mann-Whitney test, not significant; Fig. 1G) were not different, Sholl analysis showed altered organization of MIA apical morphology compared with control neurons (Fig. 1H). Thus, following MIA, neurons have a bigger dendritic arbor at birth.

\section{MIA Enhances Glutamatergic Postsynaptic Currents at Birth}

We further evaluated glutamatergic and GABAergic activity using whole-cell voltage clamp recordings to investigate spontaneous glutamatergic and GABAergic postsynaptic currents (sGlu PSCs and sGABA PSCs, respectively). In PO CA3 pyramidal neurons of MIA offspring, the frequency of sGlu PSCs was enhanced compared with saline ones $(0.57 \pm 0.132 \mathrm{~Hz}$ vs. $0.23 \pm 0.049 \mathrm{~Hz}$; MannWhitney test, $P<0.05$; Fig. $2 A-C)$, with no difference of amplitude $(8.03 \pm 1.162 \mathrm{pA}$ vs. $7.48 \pm 0.784 \mathrm{pA}$; Mann-Whitney test, not significant; Fig. $2 A, B, D)$. In contrast, the frequency and amplitude of sGABA PSCs at PO was not different between MIA and control pyramidal neurons $(0.34 \pm 0.116 \mathrm{~Hz} ; 41.06 \pm 2 \mathrm{pA}$ vs. $0.18 \pm$ $0.03 \mathrm{~Hz} ; 43.01 \pm 2.94 \mathrm{pA}$; Mann-Whitney test, not significant; Fig. 2E-H). Therefore, Poly(I:C)-induced MIA increases glutamatergic spontaneous activity of CA3 pyramidal neurons at birth.

\section{At Birth the Pairwise Correlation of Active Cells is Increased After MIA}

Hippocampal CA3 early correlated neuronal activity was further investigated in MIA offspring by 2-photon calcium imaging of P0 acute brain slices (Fig. 3A.1). Semiautomated detection of cells (Fig. 3.A.2) and evaluation of calcium activity (Fig. 3B) revealed that the percentage of active cells was not different in MIA CA3 networks compared with saline $(39.77 \pm 3.32 \%$ vs. $36.41 \pm 3.19 \%$; Mann-Whitney test, not significant; Fig. 3C). However, the hippocampal networks of MIA offspring presented a significantly increased correlation in the calcium events occurrence in active cellular pairs (15 saline networks, 14 MIA networks; Kolmogorov-Smirnov test, $P<0.001$; Fig. 3D). Despite a tendency, no significant difference was found in the percentage of cells presenting a plateau calcium activity $(22.72 \pm$ $2.21 \%$ vs. $16.35 \pm 1.76 \%$; Mann-Whitney test, not significant; Supplementary Fig. 2A), and the distance-dependent pairwise correlation of calcium plateau cells (Kolmogorov-Smirnov, $\mathrm{P}=$ 0.06 , not significant; Supplementary Fig. $2 B-E$ ) between groups. Hence, more neurons generate correlated activity at birth in MIA than control hippocampi networks. 
A

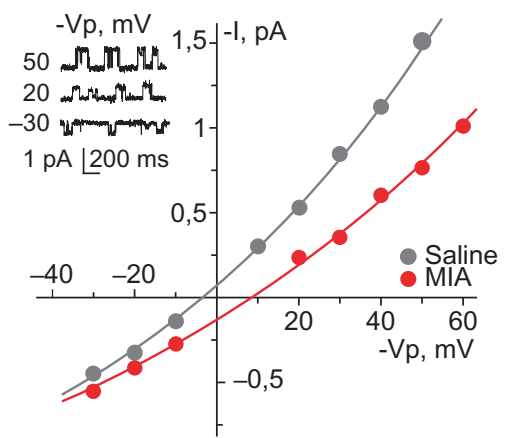

C

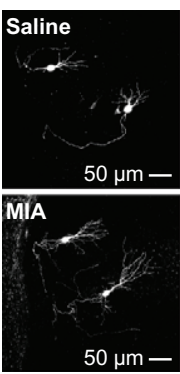

$\mathrm{F}$

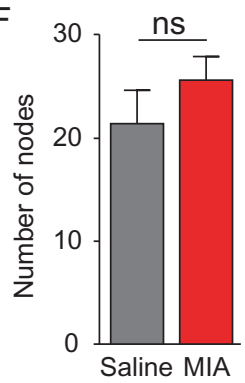

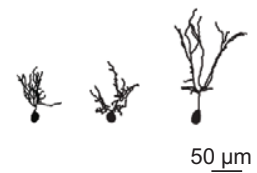

$50 \underline{\mu m}$

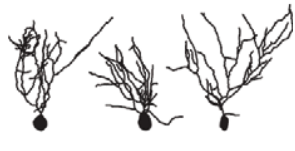

$\mathrm{G}$

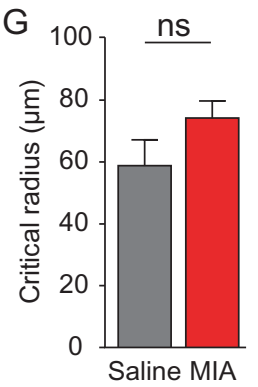

B

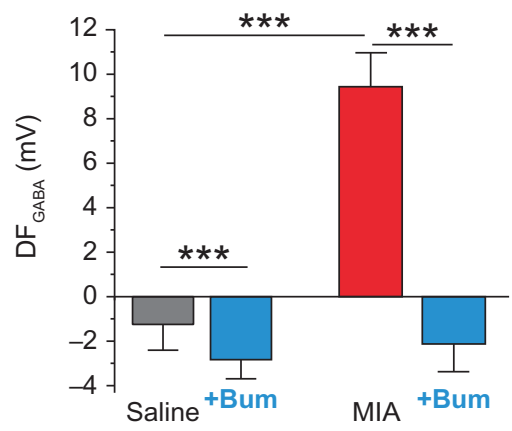

D

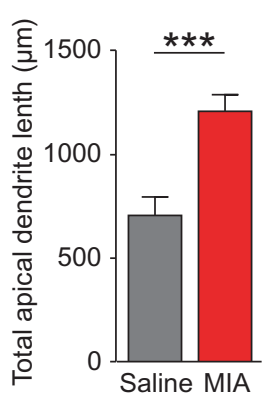

$E$

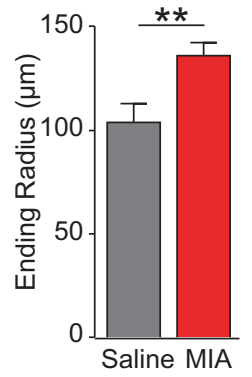

$\mathrm{H}$

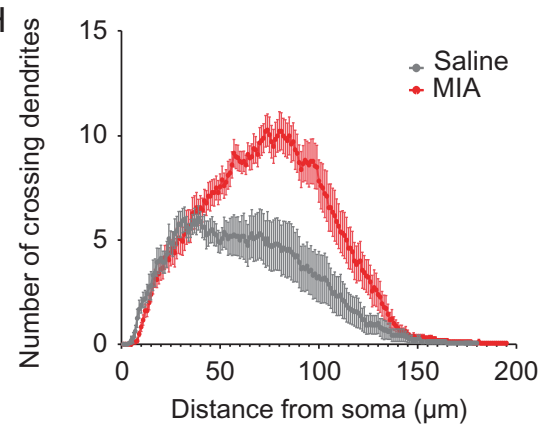

Figure 1. MIA-induced depolarizing GABA action and altered apical dendritic arborization in CA3 pyramidal neurons at birth. (A) Representative I/V curves of hippocampal CA3 pyramidal cells at P0 using cell-attached recordings of single-GABA $\mathrm{R}$ channels for the estimation of the DF $\mathrm{GABA}_{\mathrm{A}}$. Each dot shows currents recorded as a

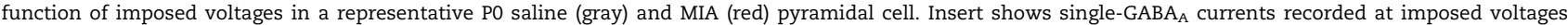
$(-\mathrm{Vp}, \mathrm{mV})$ in a control saline $\mathrm{PO}$ pyramidal cell. (B) Average values of $\mathrm{DF}_{\mathrm{GABA}}$ in saline $(n=51$ cells) and MIA ( $n=52$ cells) neurons, with bumetanide action on $\mathrm{DF}$ GABA $\left(10 \mu \mathrm{M}\right.$, blue; Saline+Bum $n=25$ cells; MIA+Bum $n=39$ cells). Two-tailed T-test, ${ }^{* * *} \mathrm{P}<0.001$. (C) Confocal images of biocytin-filled CA3 pyramidal neurons from saline (top) and MIA (bottom) PO offspring and representative reconstructed apical arbors. (D) The total length of apical dendrites is increased in MIA P0 pyramidal neurons compared with saline. $(E)$ The ending radius of MIA P0 pyramidal neurons is larger than saline controls. (F) The mean number of nodes per radius is similar between control and MIA neurons. $(G)$ The critical radius, at which neurons show the maximum number of intersections, is not significantly different between control and MIA neurons. (H) Sholl analysis illustrating morphological differences of apical dendrites shows altered dendritic arborization in MIA (red) neurons compared with saline (gray). ( $D-H)$ Saline neurons $n=16$; MIA neurons $n=18$ cells. Mann-Whitney test, ${ }^{* * *} P<0.001,{ }^{* *} P<0.005$.

\section{The Depolarizing Actions of GABA are Persistent in MIA Offspring and Associated with an Excitatory Activity}

We further evaluated if the GABA polarity alterations observed on the day of birth persisted in prewean juvenile MIA offspring. The $\mathrm{DF}_{\mathrm{GABA}}$ continued to be depolarizing in MIA CA3 pyramidal neurons at P14-15 $(11.7 \pm 5.1 \mathrm{mV})$, whereas it was slightly hyperpolarizing in control neurons $(-3.2 \pm 4.1 \mathrm{mV}$; 2-tailed T-test, $P<0.001$; Fig. 4A,B). We next assessed if the depolarizing action of GABA was associated with neuronal excitation using the specific $G_{A B A} R$ agonist isoguvacine in cell-attached configuration. As expected, isoguvacine decreased the basal spiking frequency of neurons recorded in control animals (67.24 \pm $12.87 \%$ of basal spiking; paired T-test, $P<0.05$; Fig. 4C,D), indicating that GABA exerts an inhibitory action on saline neurons. In contrast, isoguvacine increased the basal spiking frequency of MIA neurons (137.1 $\pm 11.5 \%$; paired T-test, $P<0.05$; Fig. $4 C, D)$, indicative of an excitatory action of GABA at P14-15. Spiking activity was similar before the application of isoguvacine and after washout of the drug under both MIA and saline conditions (Fig. 4D, right). Consequently, MIA induces persistent GABAdepolarizing and -excitatory activities in pyramidal hippocampal neurons of prewean juvenile pups.

\section{Glutamatergic PSCs Frequency and Amplitude are Enhanced in Prewean MIA Offspring}

Spontaneous PSC recordings were performed in pyramidal neurons at P14-15 to assess network activity in CA3 after MIA. The frequency of sGlu PSCs was increased in MIA compared with saline neurons $(21.45 \pm 1.83 \mathrm{~Hz}$ vs. $13.4 \pm 1.54 \mathrm{~Hz}$; MannWhitney test, $P<0.005$; Fig. $5 A-C)$ and so was the amplitude (14.59 \pm 0.91 pA vs. $11.8 \pm 0.69$ pA; Mann-Whitney test, $P<0.05$; 
A

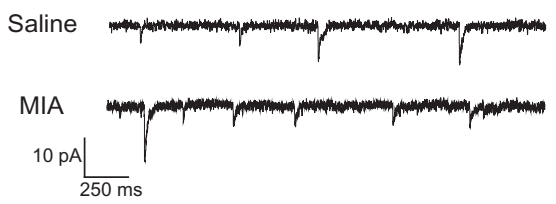

C

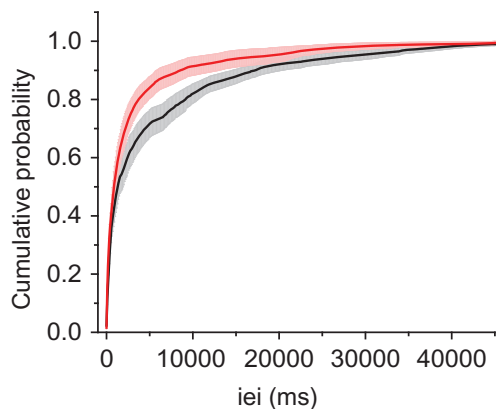

$\mathrm{E}$

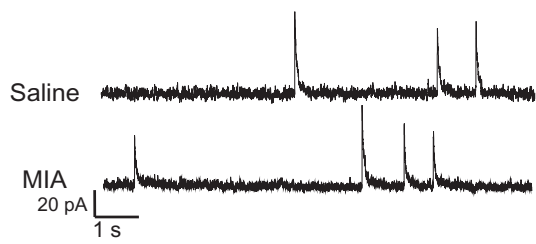

G

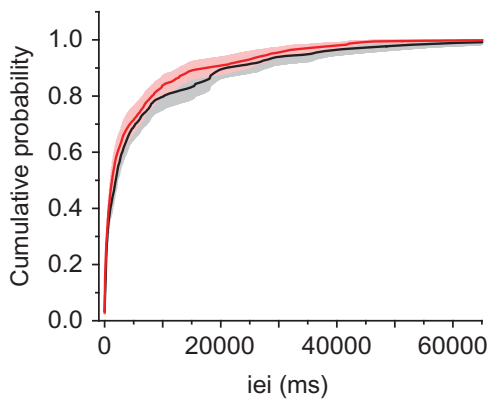

B

D
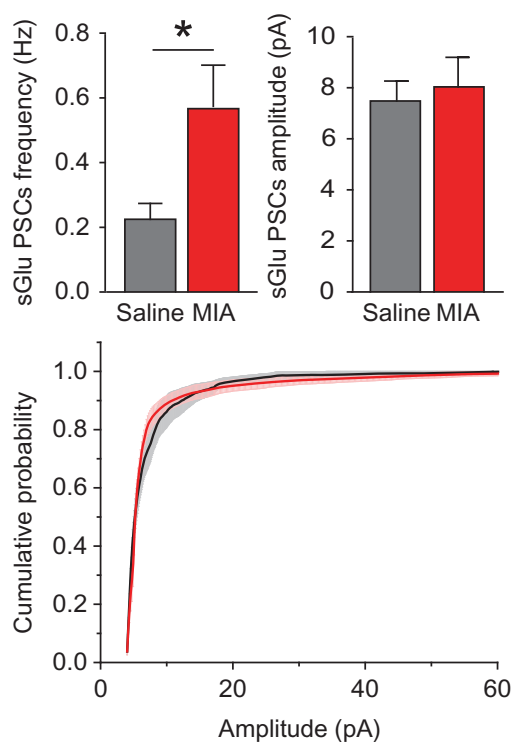

$\mathrm{F}$

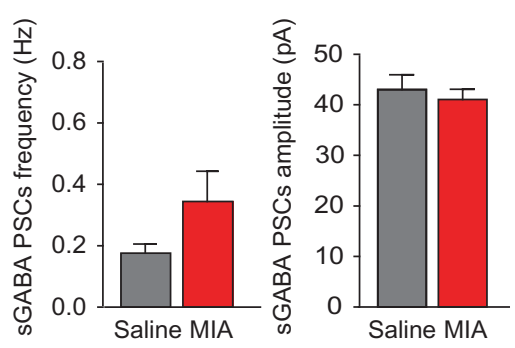

$\mathrm{H}$

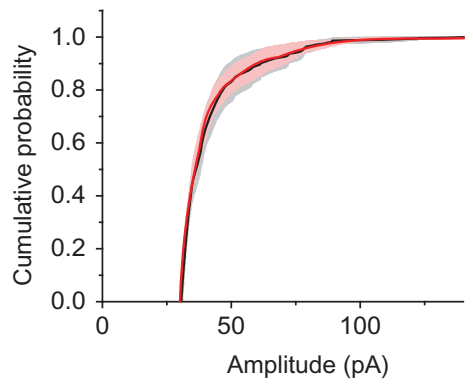

Figure 2. Enhanced frequency of glutamatergic postsynaptic currents at birth after MIA. (A) Representative traces of sGlu PSCs and (E) sGABA PSCs recorded in wholecell voltage clamp configuration of PO pyramidal cells of saline and MIA offspring. (B) The frequency of sGlu PSCs is increased in MIA ( $n=11$ cells) compared with saline ( $n=10$ cells). (C) Averaged cumulative distribution of sGlu PSCs interevent interval (iei) and (D) amplitude for the pooled dataset represented in (B). (F) The frequency and amplitude of sGABA PSCs is similar between saline ( $n=10$ cells) and MIA ( $n=12$ cells) pyramidal neurons. (G) Averaged cumulative distribution of sGABA PSCs iei and $(\mathrm{H})$ amplitude for the pooled dataset represented in $(F)$. Mann-Whitney test, ${ }^{*} \mathrm{P}<0.05$.

A1

B

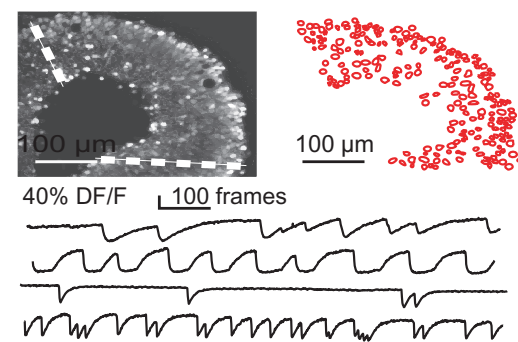

A2

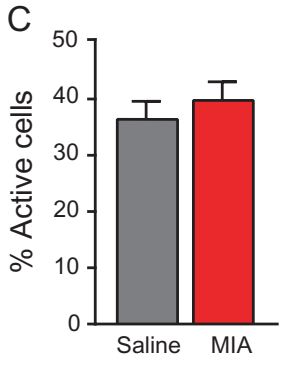

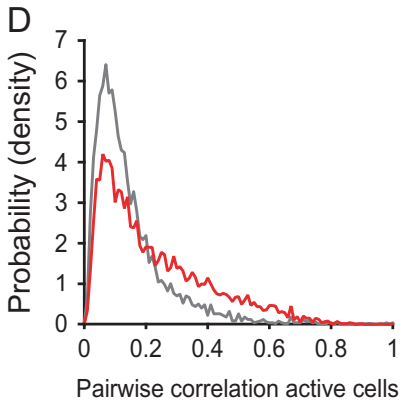

Figure 3. MIA-induced increased pairwise correlation of active cells in CA3 hippocampal networks at birth. (A.1) Representative image of a P0 hippocampal slice loaded with the Fura-2AM fluorescent calcium sensor and (A.2) corresponding semiautomated cells contours detection. Dashed lines on picture define the CA3 area in which further steps of analysis were carried out. (B) Representative traces of fluorescence emitted by cells loaded with Fura-2AM. Each trace corresponds to fluorescence variations emitted by a single cell. (C) The percentage of active cells in P0 CA3 networks is similar in saline ( $n=15$ networks) and MIA conditions ( $n=14$ networks). Mann-Whitney test not significant. (D) Correlation between the calcium events timing in pairs of active cells. Only pairs showing correlations above zero, i.e., with at least one overlapping event, were pooled and included in the plot. Kolmogorov-Smirnov test, $P<0.001$. 
A
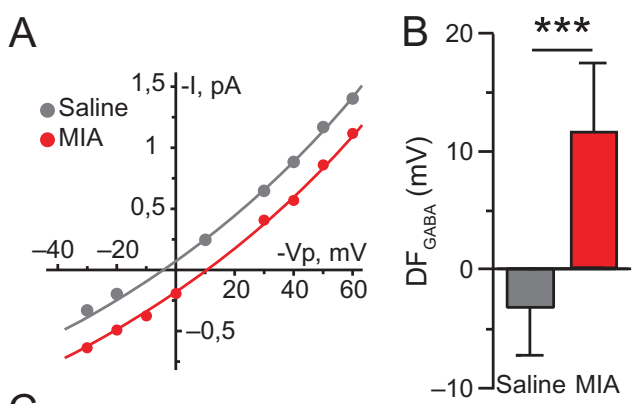

C
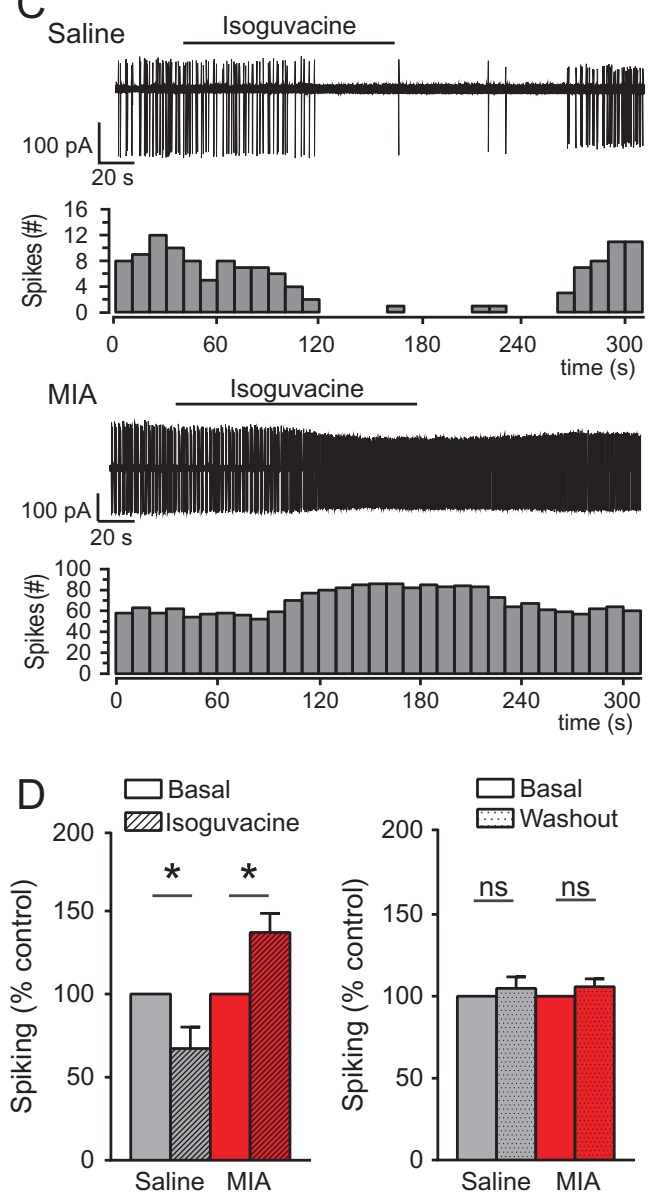

Figure 4. The driving force of GABA remains depolarizing in 2-week-old MIA offspring and is accompanied by excitatory GABA action in CA3 pyramidal neurons. (A) Representative I/V curves of P14-15 hippocampal CA3 pyramidal cells recordings of $\mathrm{GABA}_{\mathrm{A}} \mathrm{R}$ single-channel currents for the estimation of the $\mathrm{DF}_{\mathrm{GABA}}$ in a representative saline (gray) and MIA (red) pyramidal cell. (B) Average values of $\mathrm{DF}_{\mathrm{GABA}}$ in saline ( $n=24$ cells) and MIA ( $n=19$ cells) neurons. Two-tailed T-test ${ }^{* * *} \mathrm{P}<0.001$. (C) Representative traces of P14-15 pyramidal cells spiking activity using cell-attached recordings and associated spike quantification per $10 \mathrm{~s}$ bin in saline (upper panels) and MIA conditions (bottom panels). Bar above traces indicates time window during which isoguvacine $(10 \mu \mathrm{M})$ was bath applied. (D) Mean spiking frequency of saline $(n=9$ cells) and MIA ( $n=9$ cells) P14-15 pyramidal neurons upon isoguvacine application (left panel) and during the washout recording period (right panel) were normalized to the basal spiking frequency. Paired T-test, ${ }^{*} \mathrm{P}<0.05$.

Fig. $5 A, B, D)$. In contrast, the frequency and amplitude of sGABA PSCs recorded in MIA offspring neurons were similar to those recorded in neurons of control offspring $(8.88 \pm 1.31 \mathrm{~Hz} ; 63.73 \pm$ $3.77 \mathrm{pA}$, respectively, vs. $6.83 \pm 1.48 \mathrm{~Hz} ; 61.77 \pm 3.50 \mathrm{pA}$, respectively; Mann-Whitney test, not significant; Fig. 5E-H). Therefore, MIA enhances sGlu PSCs at P14-15.

\section{Discussion}

Epidemiological studies have stressed the importance of gestational maternal infection and inflammatory processes as risk factors for developmental disorders in offspring (Patterson 2002, 2009; Atladóttir et al. 2010, 2012; Brown 2012; Knuesel et al. 2014; Lyall et al. 2014; Zerbo et al. 2015). However, whether and how MIA hinders developmental sequences is not known. To the best of our knowledge, our results provide the first evidence that MIA produces already at birth important physiological and morphological changes in the hippocampus of mice. These results shed new light on the deleterious effects of in utero MIA on offspring brain physiology and functional network development already at birth and its long-term consequences, and are in accordance with the recent demonstration of a delayed excitatory/inhibitory shift of GABA in P20 cortical neurons of MIA rat offspring (Corradini et al. 2018). Specifically, we show that MIA alters spontaneous glutamatergic activity and GABAergic polarity, affecting hippocampal circuit maturation during the critical period of birth and persisting into the end of the second postnatal week. These results are in keeping with the neuroarcheology concept (Ben-Ari 2008), according to which intrauterine insults lead to long-term changes by deviating developmental sequences with the presence in adult networks of neurons endowed with immature features.

Birth marks the developmental transition from a stabilized environment to a continuous flow of unpredictable stimuli, therefore initiating major physiological adaptations. The fetal brain must then quickly overcome the major ongoing physiological changes, without being affected by the harmful side effects of the acute stressors during the delivery process (Lagercrantz and Bistoletti 1977). Furthermore, dysregulated GABAergic polarity on the day of birth has been identified as a critical signature of developmental brain disorders (Ben-Ari 2015). Indeed, we previously showed that the protective inhibitory action of GABA at birth was abolished in hippocampal neurons of VPA and FRX rodent models of ASD (Tyzio et al. 2014), accompanied by lasting imbalanced sGlu PSCs and maintained depolarizing and excitatory GABA. The present study reveals that the environmental insult of MIA similarly alters GABA action at birth by dysregulating intracellular chloride concentration, as suggested by the acute application of the NKCC1 antagonist bumetanide that rescued the polarity of GABA. In addition, our present results show hyperactive developing hippocampal networks after MIA already at birth and a similar lasting alteration of sGlu PSCs accompanied of sustained depolarizing and excitatory GABA actions.

Several reports have shown alterations in the excitatory versus inhibitory balance after MIA as well as increased susceptibility for seizures in stimulated conditions. Indeed, adult offspring from Poly(I:C) MIA subjected to an epilepsy protocol produced by focal electrical stimulation in the hippocampus (i.e., kindling model of epilepsy) was shown to exhibit increased hippocampal excitability and accelerated kindling rate, with increased seizure susceptibility persisting 2 weeks later (Pineda et al. 2013). Increased susceptibility to seizures following kainic acid treatment was also reported in 3-month-old MIA offspring (Corradini et al. 2018). Interestingly, parvalbumin GABAergic neurons are impacted by MIA with decreased GAD67 protein levels in the dorsal hippocampus (Dickerson et al. 2014), reduced number and density in the dentate gyrus (Piontkewitz et al. 2012; Zhang and van Praag 2015) 


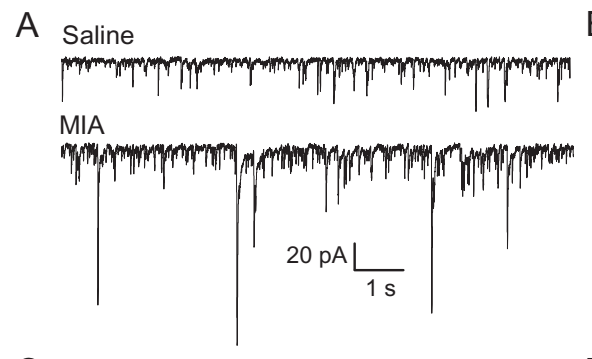

C

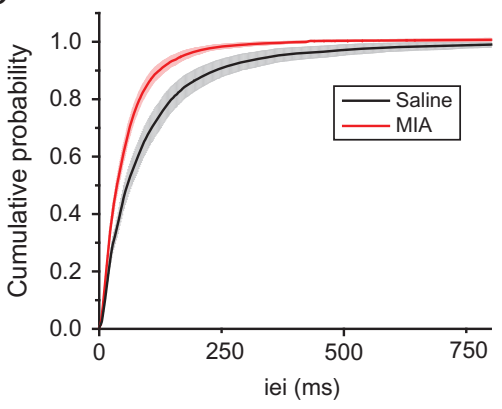

E

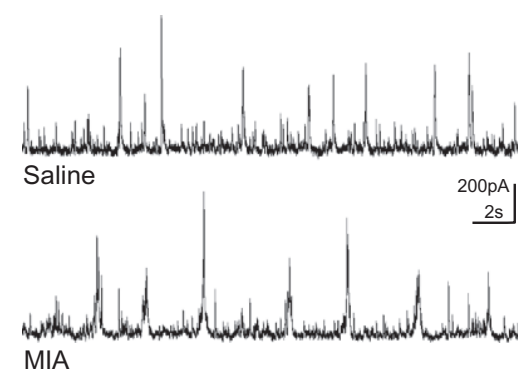

G

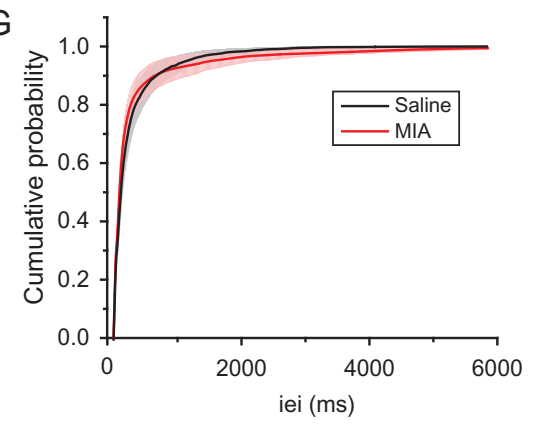

\section{B}

D
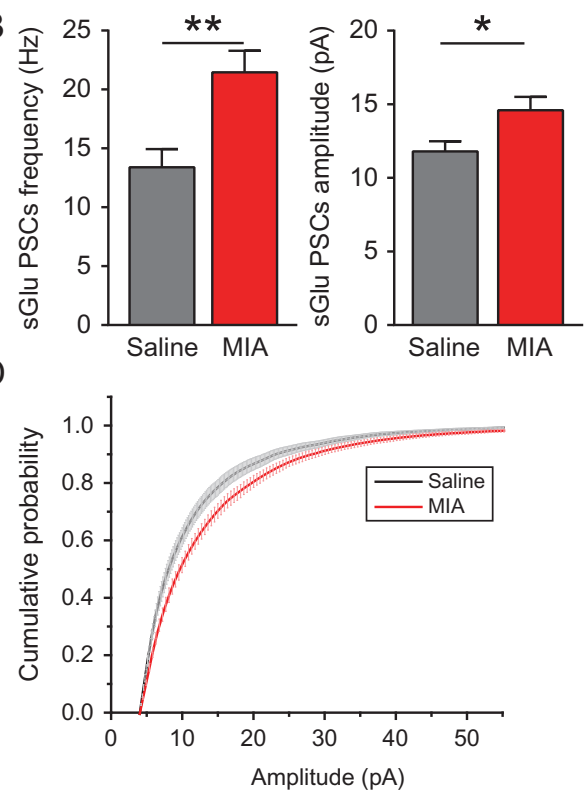

F
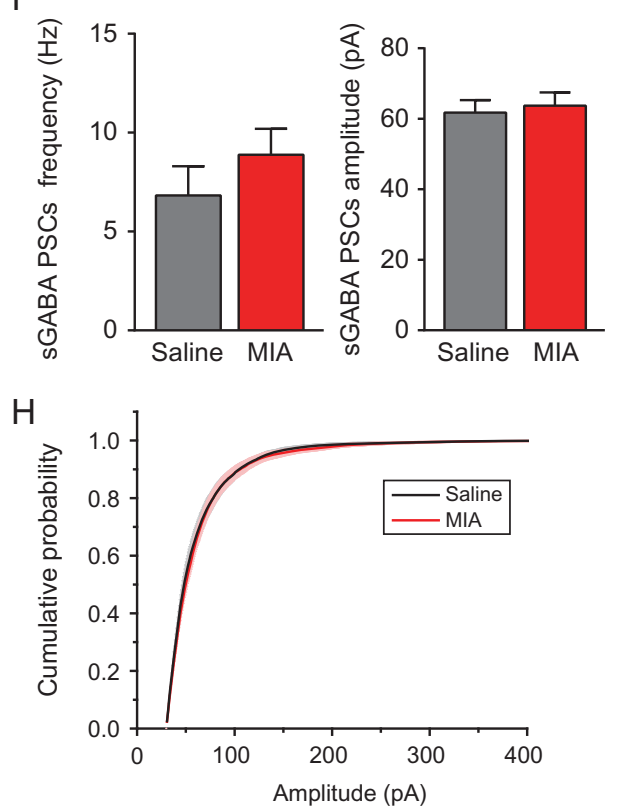

Figure 5. Excitatory inputs remain elevated at P14-15 in CA3 pyramidal neurons of MIA offspring. (A) Representative traces of sGlu PSCs and (E) sGABA PSCs recorded in whole-cell voltage clamp configuration of P14-15 CA3 pyramidal neurons of saline or MIA offspring. (B) The frequency and amplitude of sGlu PSCs are increased in MIA pyramidal neurons ( $n=26$ cells) compared with saline ( $n=18$ cells). (C) Averaged cumulative distribution of sGlu PSCs interevent interval (iei) and (D) amplitude for the pooled dataset represented in (B). (F) The frequency and amplitude of sGABA PSCs are similar between saline $(n=14$ cells) and MIA ( $n=19$ cells) neurons. $(G)$ Averaged cumulative distribution of sGABA PSCs iei and $(H)$ amplitude for the pooled dataset represented in $(F)$. Mann-Whitney test, ${ }^{*} P<0.05,{ }^{* *} P<0.005$.

and decreased input in the medial prefrontal cortex (Canetta et al. 2016). A developmental study by Paylor and colleagues highlighted an age-dependent and region-specific reduction of perineuronal nets in the medial prelimbic cortex and amygdala of MIA offspring (Paylor et al. 2016). In mature dentate granule cells recorded after MIA, intrinsic properties are altered and the frequency of miniature inhibitory postsynaptic currents (mIPSCs) is reduced (Zhang and van Praag 2015). Increased sEPSCs amplitude has also been reported in neurons of the basolateral amygdala in MIA mice (Li et al. 2018). Thus, in utero exposure to MIA disrupts the inhibitory/excitatory balance from birth and into adulthood.
Our results further show that the apical morphology of hippocampal CA3 pyramidal neurons from MIA newborn offspring is hypertrophied and strongly altered in shape. Whether these alterations are permanent remains to be investigated. In addition, these morphological alterations might be structure dependent and depend on the developmental stage at which the MIA insult occurred (Meyer 2006; Meyer et al. 2008). Indeed, LPSinduced MIA led to reorganized apical dendritic tree architecture and to increased apical dendrites complexity in P14-21 mouse pyramidal cells from layer II primary visual cortex (Gao et al. 2015), also see (Fernández de Cossío et al. 2017). In contrast, in adult Poly(I:C)-induced MIA mouse offspring, the total 
number and length of dendritic intersections of hippocampal dentate granule cells are decreased (Li et al. 2014; Zhang and van Praag 2015), and dendritic architecture of medial prefrontal cortex pyramidal cells is altered (Li et al. 2014).

Altered dendritic architecture and increased spanning of apical arbors might result from MIA-induced dysregulation of neurotrophic cues. Indeed, depolarizing GABA actions at birth are likely to contribute to the apical dendritic overgrowth by modulating neuritic outgrowth via calcium-dependent mechanisms (Barbin et al. 1993; Owens and Kriegstein 2002; Represa and Ben-Ari 2005; Wang and Kriegstein 2009). This in turn can regulate brain-derived neurotrophic factor (BDNF) release and play a role on neuronal morphology (Marty et al. 1996; Fiorentino et al. 2009; Kuczewski et al. 2011). Therefore, from a network perspective, MIA might enhance GABAergic neurons growth and synaptogenesis (through depolarizing GABA at birth) (Fiorentino et al. 2009), thereby increasing the probability of synaptic contacts between interneurons and pyramidal cells and facilitating synchronous activity between active cellular pairs.

Depolarizing GABA action at birth might also facilitate glutamatergic NMDA receptors-mediated currents by removing the intracellular magnesium block from NMDA receptors (Leinekugel et al. 1997) leading to the uncovered increase in glutamatergic input after MIA. In addition, depolarizing GABA facilitates the formation of excitatory synapses in neocortical neurons (Owens and Kriegstein 2002; Wang and Kriegstein 2009) and an enhanced glutamatergic synaptogenesis. Thus, the absence of the switch of GABA action at birth after MIA could lead to an enhanced glutamatergic synaptogenesis and activity. This is in accord with our previous report, in which restoring the depolarizing to hyperpolarizing switch of GABA at birth in 2 rodent models of autism also restored normal spontaneous glutamatergic activity at P15 in the offspring (Tyzio et al. 2014).

Although not fully understood, a general picture is starting to emerge on the likely sequence of events that occur after MIA. Choi and colleagues have shown that MIA activates the interleukin-17 pathway (through IL-17a) leading to an abnormal cortical development as early as E14.5 in mice (Choi et al. 2016). The MIA-induced resulting dysplastic cortical patches are responsible of the abnormal behaviors observed in adult mice (Shin Yim et al., 2017). Furthermore, several other intermediate steps occurring after the MIA insult have been identified. Specifically, in utero Poly(I:C) injection increases interleukin-1 $\beta$ (IL-1 $\beta$ ), interleukin-6 (IL-6), and TNF- $\alpha$ levels (Giovanoli, Notter, et al. 2015; Giovanoli, Weber-Stadlbauer, et al. 2016; Corradini et al. 2018). Exposure to IL- $1 \beta$ and TNF- $\alpha$ upregulates the Na-K$\mathrm{Cl}$ cotransporter NKCC1 gene mRNA and protein expression in human endothelial cells of umbilical vein (Topper et al. 1997) and cultured astrocytes in a dose-dependent manner (Huang et al. 2014). In addition, Poly(I:C) alters the ratio of NKCC1 and KCC2 protein and mRNA levels in cortical homogenates of P20 mice in a cytokine-dependent way (viz. IL-6 and IL-1 $\beta$ ) (Corradini et al. 2018) leading to an abolishment of the excitatory to inhibitory shift of GABA. Therefore, our results on the Poly(I:C)-dependent bumetanide-sensitive alteration of GABA polarity in the hippocampus at birth and at the end of the second postnatal week suggest that an MIA-elicited inflammatory response might trigger an early dysregulation in the expression of chloride cotransporters leading to an alteration of developing networks. Yet, the exact links between an event restricted to labor and birth and the long-term deleterious sequels remain elusive. The fact that maternal bumetanide treatment during that precise short period is sufficient to attenuate the behavioral and electrical features of autism illustrates the importance of this critical period that can reduce or aggravate the effects of intrauterine insults (Tyzio et al. 2014).

In conclusion, CA3 hippocampal neurons of MIA offspring show already at birth changes that are reminiscent of those occurring in animal models of ASD and other disorders (BenAri 2017). Hence, despite their different behavioral, physiological, and clinical features, neurodevelopmental disorders seem to share some pathophysiological commonalities, notably early alterations of the polarity of GABAergic activity.

\section{Supplementary Material}

Supplementary material is available at Cerebral Cortex online.

\section{Funding}

Neurochlore; Fondation Bettencourt Schueller; and a Fellowship CIFRE-ANRT (2014/1057) (to Amandine Fernandez).

\section{Notes}

The authors want to thank Philippe Naquet for his scientific input and the establishment of the MIA protocol. A.F. gratefully thanks Sanaz Eftekhari, Maxime Billon-Grand, Laurie-Anne Gouty-Colomer, Morgane Chiesa, Robin Cloarec, Baptiste Riffault, Amandine Dufour and Alexandre Pons-Bennaceur for their experimental and technical support. Address correspondence to Yehezkel Ben-Ari and Diana C. Ferrari: Neurochlore, Ben-Ari Institute of Neuroarcheology (IBEN), Bâtiment Beret-Delaage, Parc scientifique et technologique de Luminy, Zone Luminy Biotech Entreprises, case 922, 163 avenue de Luminy, 13288 Marseille cedex 09, France.

\section{Competing financial interests}

Y. Ben-Ari, D.C. Ferrari, N. Burnashev, R. Tyzio and N. Lozovaya are shareholders of Neurochlore, a biotech company dedicated to the development of treatments for children with autism. Y. Ben-Ari is also the CEO of the company.

\section{References}

Atladóttir HO, Henriksen TB, Schendel DE, Parner ET. 2012. Autism after infection, febrile episodes, and antibiotic use during pregnancy: an exploratory study. Pediatrics. 130:e1447-e1454.

Atladóttir HÓ, Thorsen P, Østergaard L, Schendel DE, Lemcke S, Abdallah M, Parner ET. 2010. Maternal infection requiring hospitalization during pregnancy and autism spectrum disorders. J Autism Dev Disord. 40:1423-1430.

Barbin G, Pollard H, Gaïarsa JL, Ben-Ari Y. 1993. Involvement of GABAA receptors in the outgrowth of cultured hippocampal neurons. Neurosci Lett. 152:150-154.

Ben-Ari Y. 2008. Neuro-archaeology: pre-symptomatic architecture and signature of neurological disorders. Trends Neurosci. 31:626-636.

Ben-Ari Y. 2015. Is birth a critical period in the pathogenesis of autism spectrum disorders? Nat Rev Neurosci. 16:498-505.

Ben-Ari Y. 2017. NKCC1 chloride importer antagonists attenuate many neurological and psychiatric disorders. Trends Neurosci. 40:536-554.

Bilbo SD, Block CL, Bolton JL, Hanamsagar R, Tran PK. 2018. Beyond infection-maternal immune activation by environmental factors, microglial development, and relevance for autism spectrum disorders. Exp Neurol. 299:241-251. 
Boksa P, Zhang Y, Amritraj A, Kar S. 2006. Birth insults involving hypoxia produce long-term increases in hippocampal [125I]insulin-like growth factor-I and -II receptor binding in the rat. Neuroscience. 139:451-462.

Bonifazi P, Goldin M, Picardo MA, Jorquera I, Cattani A, Bianconi G, Represa A, Ben-Ari Y, Cossart R. 2009. GABAergic hub neurons orchestrate synchrony in developing hippocampal networks. Science. 326:1419-1424.

Brander G, Rydell M, Kuja-Halkola R, Fernández de la Cruz L, Lichtenstein P, Serlachius E, Rück C, Almqvist C, D'Onofrio BM, Larsson H, et al. 2018. Perinatal risk factors in Tourette's and chronic tic disorders: a total population sibling comparison study. Mol Psychiatry. 23:1189-1197.

Brown AS. 2012. Epidemiologic studies of exposure to prenatal infection and risk of schizophrenia and autism. Dev Neurobiol. 72:1272-1276

Canetta S, Bolkan S, Padilla-Coreano N, Song LJ, Sahn R, Harrison NL, Gordon JA, Brown A, Kellendonk C. 2016. Maternal immune activation leads to selective functional deficits in offspring parvalbumin interneurons. Mol Psychiatry. 21:956-968.

Choi GB, Yim YS, Wong H, Kim S, Kim H, Kim SV, Hoeffer CA, Littman DR, Huh JR. 2016. The maternal interleukin-17a pathway in mice promotes autism-like phenotypes in offspring. Science. 351:933-939.

Chudal R, Sourander A, Polo-Kantola P, Hinkka-Yli-Salomäki S, Lehti V, Sucksdorff D, Gissler M, Brown AS. 2014. Perinatal factors and the risk of bipolar disorder in Finland. J Affect Disord. 155:75-80.

Corradini I, Focchi E, Rasile M, Morini R, Desiato G, Tomasoni R, Lizier M, Ghirardini E, Fesce R, Morone D, et al. 2018. Maternal immune activation delays excitatory-to-inhibitory gamma-aminobutyric acid switch in offspring. Biol Psychiatry. 83:680-691.

Crépel V, Aronov D, Jorquera I, Represa A, Ben-Ari Y, Cossart R. 2007. A Parturition-associated nonsynaptic coherent activity pattern in the developing hippocampus. Neuron. 54:105-120.

Custódio CS, Mello BSF, Filho AJMC, de Carvalho Lima CN, Cordeiro RC, Miyajima F, Réus GZ, Vasconcelos SMM, Barichello T, Quevedo J, et al. 2018. Neonatal immune challenge with lipopolysaccharide triggers long-lasting sex- and age-related behavioral and immune/neurotrophic alterations in mice: relevance to autism spectrum disorders. Mol Neurobiol. 55:3775-3788.

Dean JM, Shi Z, Fleiss B, Gunn KC, Groenendaal F, Van Bel F, Derrick M, Juul SE, Tan S, Gressens P, et al. 2015. A critical review of models of perinatal infection. Dev Neurosci. 37:289-304.

Dehorter N, Michel F, Marissal T, Rotrou Y, Matrot B, Lopez C, Humphries M, Hammond C. 2011. Onset of pup locomotion coincides with loss of NR2C/D-mediated cortico-striatal EPSCs and dampening of striatal network immature activity. Front Cell Neurosci. 5. doi: 10.3389/fncel.2011.00024.

Dickerson DD, Overeem KA, Wolff AR, Williams JM, Abraham WC, Bilkey DK. 2014. Association of aberrant neural synchrony and altered GAD67 expression following exposure to maternal immune activation, a risk factor for schizophrenia. Transl Psychiatry. 4:e418.

Eftekhari S, Shahrokhi A, Tsintsadze V, Nardou R, Brouchoud C, Conesa M, Burnashev N, Ferrari DC, Ben-Ari Y. 2014. Response to comment on "Oxytocin-mediated GABA inhibition during delivery attenuates autism pathogenesis in rodent offspring". Science. 346:176.

Estes ML, Mcallister AK. 2016. Maternal immune activation: implications for neuropsychiatric disorders. Science. 353 (6301):772-777.
Fernández de Cossío L, Guzmán A, van der Veldt S, Luheshi GN. 2017. Prenatal infection leads to ASD-like behavior and altered synaptic pruning in the mouse offspring. Brain Behav Immun. 63:88-98.

Ferrari DC, Mdzomba BJ, Dehorter N, Lopez C, Michel FJ, Libersat F, Hammond C. 2012. Midbrain dopaminergic neurons generate calcium and sodium currents and release dopamine in the striatum of pups. Front Cell Neurosci. 6:1-9.

Fiorentino H, Kuczewski N, Diabira D, Ferrand N, Pangalos MN, Porcher C, Gaiarsa J-L. 2009. GABAB receptor activation triggers BDNF release and promotes the maturation of GABAergic synapses. J Neurosci. 29:11650-11661.

Gao Y, Liu L, Li Q, Wang Y. 2015. Differential alterations in the morphology and electrophysiology of layer II pyramidal cells in the primary visual cortex of a mouse model prenatally exposed to LPS. Neurosci Lett. 591:138-143.

Giovanoli S, Notter T, Richetto J, Labouesse MA, Vuillermot S, Riva MA, Meyer U. 2015. Late prenatal immune activation causes hippocampal deficits in the absence of persistent inflammation across aging. J Neuroinflammation. 12: 1-18.

Giovanoli S, Weber-Stadlbauer U, Schedlowski M, Meyer U, Engler H. 2016. Prenatal immune activation causes hippocampal synaptic deficits in the absence of overt microglia anomalies. Brain Behav Immun. 55:25-38.

Gouty-Colomer LA, Michel FJ, Baude A, Lopez-Pauchet C, Dufour A, Cossart R, Hammond C. 2018. Mouse subthalamic nucleus neurons with local axon collaterals. J Comp Neurol. 526:275-284

Hsiao EY, Patterson PH. 2011. Activation of the maternal immune system induces endocrine changes in the placenta via IL-6. Brain Behav Immun. 25:604-615.

Huang LQ, Zhu GF, Deng YY, Jiang WQ, Fang M, Chen CB, Cao W, Wen MY, Han YL, Zeng HK. 2014. Hypertonic saline alleviates cerebral edema by inhibiting microglia-derived TNF- $\alpha$ and IL-1 $\beta$-induced Na-K-Cl Cotransporter upregulation. J Neuroinflammation. 11:1-20. doi: 10.1186/ 1742-2094-11-102.

Khazipov R, Ragozzino D, Bregestovski P. 1995. Kinetics and Mg2+ block of N-methyl-D-aspartate receptor channels during postnatal development of hippocampal CA3 pyramidal neurons. Neuroscience. 69:1057-1065.

Kim S, Kim H, Yim YS, Ha S, Atarashi K, Tan TG, Longman RS, Honda K, Littman DR, Choi GB, et al. 2017. Maternal gut bacteria promote neurodevelopmental abnormalities in mouse offspring. Nature. 549(7673):528-532.

Kirsten TB, Bernardi MM. 2017. Prenatal lipopolysaccharide induces hypothalamic dopaminergic hypoactivity and autistic-like behaviors: repetitive self-grooming and stereotypies. Behav Brain Res. 331:25-29.

Knuesel I, Chicha L, Britschgi M, Schobel SA, Bodmer M, Hellings JA, Toovey S, Prinssen EP. 2014. Maternal immune activation and abnormal brain development across CNS disorders. Nat Rev Neurol. 10:643-660.

Kuczewski N, Fuchs C, Ferrand N, Jovanovic JN, Gaiarsa JL, Porcher C. 2011. Mechanism of GABAB receptor-induced BDNF secretion and promotion of GABAA receptor membrane expression. J Neurochem. 118:533-545.

Lagercrantz H, Bistoletti P. 1977. Catecholamine release in the newborn infant at birth. Pediatr Res. 11:889-893.

Leinekugel X, Medina I, Khalilov I, Ben-Ari Y, Khazipov R. 1997. $\mathrm{Ca} 2+$ oscillations mediated by the synergistic excitatory actions of GABA(A) and NMDA receptors in the neonatal hippocampus. Neuron. 18:243-255. 
Li WY, Chang YC, Lee LJH, Lee LJ. 2014. Prenatal infection affects the neuronal architecture and cognitive function in adult mice. Dev Neurosci. 36:359-370.

Li Y, Missig G, Finger BC, Landino SM, Alexander AJ, Mokler EL, Robbins JO, Manasian Y, Kim W, Kim K-S, et al. 2018. Maternal and early postnatal immune activation produce dissociable effects on neurotransmission in mPFC-amygdala circuits. J Neurosci. 38:3358-3372.

Libersat F, Duch C. 2002. Morphometric analysis of dendritic remodeling in an identified motoneuron during postembryonic development. J Comp Neurol. 450:153-166.

Longair MH, Baker DA, Armstrong JD. 2011. Simple neurite tracer: open source software for reconstruction, visualization and analysis of neuronal processes. Bioinformatics. 27: 2453-2454.

Lyall K, Ashwood P, Van De Water J, Hertz-Picciotto I. 2014. Maternal immune-mediated conditions, autism spectrum disorders, and developmental delay. J Autism Dev Disord. 44:1546-1555.

Malkova NV, Yu CZ, Hsiao EY, Moore MJ, Patterson PH. 2012. Maternal immune activation yields offspring displaying mouse versions of the three core symptoms of autism. Brain Behav Immun. 26:607-616.

Marty S, Berninger B, Carroll P, Thoenen H. 1996. GABAergic stimulation regulates the phenotype of hippocampal interneurons through the regulation of brain-derived neurotrophic factor. Neuron. 16:565-570.

Meyer U, Nyffeler M, Engler A, Urwyler A, Schedlowski M, Knuesel I, Yee BK, Feldon J. 2006. The time of prenatal immune challenge determines the specificity of inflammation-mediated brain and behavioral pathology. J Neurosci. 26:4752-4762.

Meyer U, Nyffeler M, Yee BK, Knuesel I, Feldon J. 2008. Adult brain and behavioral pathological markers of prenatal immune challenge during early/middle and late fetal development in mice. Brain Behav Immun. 22:469-486.

Owens DF, Kriegstein AR. 2002. Is there more to GABA than synaptic inhibition? Nat Rev Neurosci. 3:715-727.

Patterson PH. 2002. Maternal infection: window on neuroimmune interactions in fetal brain development and mental illness. Curr Opin Neurobiol. 12:115-118.

Patterson PH. 2009. Immune involvement in schizophrenia and autism: etiology, pathology and animal models. Behav Brain Res. 204:313-321.

Paylor JW, Lins BR, Greba Q Moen N, De Moraes RS, Howland JG, Winship IR. 2016. Developmental disruption of perineuronal nets in the medial prefrontal cortex after maternal immune activation. Sci Rep. 6.

Pineda E, Shin D, You SJ, Auvin S, Sankar R, Mazarati A. 2013. Maternal immune activation promotes hippocampal kindling epileptogenesis in mice. Ann Neurol. 74:11-19.

Piontkewitz Y, Bernstein HG, Dobrowolny H, Bogerts B, Weiner I, Keilhoff G. 2012. Effects of risperidone treatment in adolescence on hippocampal neurogenesis, parvalbumin expression, and vascularization following prenatal immune activation in rats. Brain Behav Immun. 26:353-363.

Represa A, Ben-Ari Y. 2005. Trophic actions of GABA on neuronal development. Trends Neurosci. 28:278-283.
Richetto J, Calabrese F, Riva MA, Meyer U. 2014. Prenatal immune activation induces maturation-dependent alterations in the prefrontal GABAergic transcriptome. Schizophr Bull. 40:351-361.

Say GN, Karabekiroğlu K, Babadaği Z, Yüce M. 2016. Maternal stress and perinatal features in autism and attention deficit/ hyperactivity disorder. Pediatr Int. 58:265-269.

Schindelin J, Arganda-Carreras I, Frise E, Kaynig V, Longair M, Pietzsch T, Preibisch S, Rueden C, Saalfeld S, Schmid B, et al. 2012. Fiji: an open source platform for biological image analysis. Nat Methods. 9:676-682.

Shi L, Smith SEP, Malkova N, Tse D, Su Y, Patterson PH. 2009. Activation of the maternal immune system alters cerebellar development in the offspring. Brain Behav Immun. 23: 116-123.

Shin Yim Y, Park A, Berrios J, Lafourcade M, Pascual LM, Soares N, Yeon Kim J, Kim S, Kim H, Waisman A, et al. 2017. Reversing behavioural abnormalities in mice exposed to maternal inflammation. Nature. 549(7673):482-487.

Sholl DA. 1953. Dendritic organization in the neurons of the visual and motor cortices of the cat. J Anat. 87:387-406.

Smith SEP, Li J, Garbett K, Mirnics K, Patterson PH. 2007. Maternal immune activation alters fetal brain development through interleukin-6. J Neurosci. 27:10695-10702.

Solek CM, Farooqi N, Verly M, Lim TK, Ruthazer ES. 2018. Maternal immune activation in neurodevelopmental disorders. Dev Dyn. 247:588-619.

Topper JN, Wasserman SM, Anderson KR, Cai J, Falb D, Gimbrone MA. 1997. Expression of the bumetanide-sensitive $\mathrm{Na}-\mathrm{K}-\mathrm{Cl}$ cotransporter BSC2 is differentially regulated by fluid mechanical and inflammatory cytokine stimuli in vascular endothelium. J Clin Invest. 99:2941-2949.

Tyzio R. 2003. Membrane potential of CA3 hippocampal pyramidal cells during postnatal development. J Neurophysiol. 90: 2964-2972.

Tyzio R, Cossart R, Khalilov I, Minlebaev M, Hübner CA, Represa A, Ben-Ari Y, Khazipov R. 2006. Maternal oxytocin triggers a transient inhibitory switch in GABA signaling in the fetal brain during delivery. Science. 314:1788-1792.

Tyzio R, Nardou R, Ferrari DC, Tsintsadze T, Shahrokhi A, Eftekhari S, Khalilov I, Tsintsadze V, Brouchoud C, Chazal G, et al. 2014. Oxytocin-mediated GABA inhibition during delivery attenuates autism pathogenesis in rodent offspring. Science. 343:675-679.

Wang C, Geng H, Liu W, Zhang G. 2017. Prenatal, perinatal, and postnatal factors associated with autism: a meta-analysis. Medicine (Baltimore). 96:e6696.

Wang DD, Kriegstein AR. 2009. Defining the role of GABA in cortical development. J Physiol. 587:1873-1879.

Wolff AR, Bilkey DK. 2015. Prenatal immune activation alters hippocampal place cell firing characteristics in adult animals. Brain Behav Immun. 48:232-243.

Zerbo O, Qian Y, Yoshida C, Grether JK, Van de Water J, Croen LA. 2015. Maternal infection during pregnancy and autism spectrum disorders. J Autism Dev Disord. 45:4015-4025.

Zhang Z, van Praag H. 2015. Maternal immune activation differentially impacts mature and adult-born hippocampal neurons in male mice. Brain Behav Immun. 45:60-70. 